people ( $<29$ weeks of gestational age) of whom more than $90 \%$ were exposed to both antenatal steroids and postnatal surfactant.

Methods Lung function was assessed in 59 (34 of whom had BPD) young people. Airway function was assessed including by forced expiratory flow at $75 \%$ and $25 \%$ of the expired vital capacity $\left(\mathrm{FEF}_{75}, \mathrm{FEF}_{25-75}\right)$, forced expiratory volume in one second $\left(\mathrm{FEV}_{1}\right)$ and peak expiratory flow (PEF). Lung volumes were assessed including by total lung capacity (TLC), forced vital capacity (FVC), functional residual capacity by helium gas dilition $\left(\mathrm{FRC}_{\mathrm{He}}\right)$. Gas transfer was assessed by the diffusing capacity for carbon dioxide $\left(\mathrm{DL}_{\mathrm{CO}}\right)$. The results were converted to $\mathrm{z}$ - scores, corrected for height, sex and ethnicity using GLI reference ranges.

Results The BPD and no BPD group were of similar height and weight at assessment. The lung function results are expressed as mean $\mathrm{z}$ score (standard deviation). Airway function (FEF75 -1.31 (1.35) versus -0.64 (0.89), $\mathrm{p}=0.035$; $\mathrm{FEF}_{25-75}-1.88$ (1.42) versus -1.10 (0.84), $\mathrm{p}=0.020 ; \mathrm{FEV} 1$ $-1.41(1.44)$ versus $-0.52(1.23), p=0.017)$ and gas transfer DLCO $(-1.50(1.22)$ versus $-0.72(1.22), p=0.019)$ were significantly lower in those with BPD compared to those who had not developed BPD. Lung volumes (TLC 0.81 (1.24) versus 1.01 (0.82), $p=0.504 ;$ FVC -0.54 (1.36) versus 0.13 (1.53), $\mathrm{p}=0.086$ and FRC $\mathrm{He} 0.30$ (1.11) versus -0.16 $(1.20), \mathrm{p}=0.669)$ were similar in the BPD and no BPD groups Conclusions Airway function was significantly lower in the young people who had BPD, whereas lung volumes did not differ significantly between the two groups. Those results suggest that dysynaptic growth may be more pronounced in those who had BPD.

\section{G450 AN INTEGRATED APPROACH USING QUALITATIVE METHODS TO IDENTIFY PERCEPTIONS OF ASTHMA IN BRITISH SOUTH ASIAN AND WHITE BRITISH CHILDREN}

${ }^{1} \mathrm{~T}$ Huq, ${ }^{2} \mathrm{M}$ Lakhanpaul, ${ }^{2} \mathrm{~L}$ Manikam, ${ }^{3} \mathrm{M}$ Johnson, ${ }^{4} \mathrm{~L}$ Culley, ${ }^{5} \mathrm{~N}$ Robertson, ${ }^{6} \mathrm{D}$ Bird,
${ }^{4} \mathrm{~N}$ Hudson. ' $G$ Guy's King's and St Thomas' Hospital (GKT) School of Medical Education,
King's College London, London, UK; ${ }^{2}$ Population, Policy and Practice, Institute of Child
Health, University College London, London, UK; ${ }^{3}$ Mary Seacole Research Centre, De
Montfort University, Leicester, UK; ${ }^{4}$ School of Applied Social Sciences, De Montfort
University, Leicester, UK; ${ }^{5}$ Clinical Psychology, Centre for Medicine, University of Leicester,
Leicester, UK; ${ }^{6}$ Department of Community Paediatrics, Buckinghamshire Healthcare NHS
Trust, Wycombe Hospital, High Wycombe, UK

10.1136/archdischild-2018-rcpch.439

Background and aims Childhood asthma places a significant physical, financial, and psychological burden on patients, families, communities and the healthcare system. Current research indicates certain minority ethnic groups, especially South Asian children, encounter inequalities in asthma management and outcomes. Furthermore, children's views and aspirations are infrequently evaluated. We report here the process of encouraging children's participation in a multiphase participatory the Management in Asthma (MiA) study. The aim of this study was to explore the perceptions and experiences of asthma and its management in British South Asian (BSA) and White British (WB) children, using adapted qualitative methods.

Methods Two qualitative methods were used: semi-structured interview and prioritisation workshop, adapted to encourage children's participation (table 1). 14 themes for optimising asthma management identified from the semi-structured interviews and were used in the ranking exercises. Children ranked these themes by linear (LI, non-equal ranking), diamond (DA, equal ranking permitted) and budget pie (BP, ranking by funds allocation).

\begin{tabular}{ll} 
Abstract G450 Table 1 & \\
\hline Qualitative methods & Adaptations \\
\hline Semi-structured interview & $\begin{array}{l}\text { Drawings and text to prompt questions } \\
\text { Extended time for creative activities e.g. } \\
\end{array}$ \\
drawings \\
Health Prioritisation workshop & Trained 'peer' researchers (14-16 year-old) as facilitators \\
& Toy money and board games \\
\hline
\end{tabular}

Results Semi-structured interviews with children, with or without parents/guardian present (33 BSA and $14 \mathrm{WB}$ children with asthma aged 5-12-years-old) revealed considerable similarities in experiences of asthma, notably inadequate holistic approach to asthma management amongst healthcare professionals and the role of schools and peers in children's asthma perception and management. Barriers to health information provision existed in both groups. Consistently, WB children's perception of asthma aetiology was different from BSA children. In all the ranking methods, children (21 BSA and 1 WB child aged 5-12-years-old) highly prioritised acute attacks according to their perceived health importance. 'Strength of opinion' was demonstrated in BP, as acute attack received $£ 1430$ in total, whilst the 2 nd place theme only received $£ 610$.

Conclusion Future intervention in children with asthma may wish to focus on managing acute attacks by a holistic approach, by involving schools, families and healthcare professionals. Furthermore, ethnospecific divergent beliefs about asthma aetiology can be tackled by a targeted educational programme.

\section{G451 JUVENILE SYSTEMIC LUPUS ERYTHEMATOSUS(JSLE) PRESENTING AS IDIOPATHIC INTRACRANIAL HYPERTENSION}

${ }^{1} \mathrm{G}$ Malik, ${ }^{2} \mathrm{JE}$ Davidson, ${ }^{3} \mathrm{~V}$ Chakilam. ${ }^{1}$ General Paediatrics with Rheumatology, Royal Aberdeen Childrens Hospital, Aberdeen, UK; ${ }^{2}$ Rheumatology, Royal Hospital for Sick Children, Edinburgh, UK; ${ }^{3}$ General Paediatrics, Royal Aberdeen Childrens Hospital, Aberdeen, UK

\subsection{6/archdischild-2018-rcpch.440}

Background Idiopathic intracranial hypertension(IIH) is a rare but recognised presentation in Juvenile SLE. We describe a child who presented with IIH and was also found to have bilateral thromboembolism.

Case presentation 13 year old girl presented with a 6 week history of fatigue, headache, blurred vision, abdominal pain and painful fingers. Examination showed faint malar rash, small joint arthritis and bilateral papilledema. Diagnosis of IIH was confirmed by elevated CSF opening pressure $27 \mathrm{~cm} \mathrm{H} 2 \mathrm{O}$. Normal CSF sugar, protein and cells and neurological examination. No radiological evidence of underlying pathology including a normal CT and MR venogram. Laboratory workup revealed normocytic normochromic anaemia (9.9), lymphopenia (0.6), low platelets (110), hypocomplementemia, raised ESR (90), positive antinuclear antibody and positive anti ds 